\title{
Author Correction: Practical assessment of the performance of aluminium battery technologies
}

Ehsan Faegh, Benjamin Ng, Dillon Hayman and William E. Mustain (D)

Correction to: Nature Energy https://doi.org/10.1038/s41560-020-00728-y, published online 14 December 2020.

In the version of this Perspective originally published, the following text related to the consideration of cell components in ref. 18 was inaccurate: "Other work can fail to consider the additional infrastructure required to support new cell designs. For example, one recent report innovatively mitigates $\mathrm{Al}$ corrosion at open circuit through oil displacement. In this case, an accurate estimate of energy density was made by the authors (for example, $680 \mathrm{Wh} \mathrm{kg}^{-1}$ ) for the $\mathrm{AAB}^{18}$ ( 6 times lower than the theoretical value); however, the components required to facilitate the continuous flow of electrolyte and the storage and handling of the oil were not considered. Of course, these would add a significant amount of weight (a reasonable estimate could not be made) to the AAB pack, limiting the practical application of this type of battery."

It has now been revised to "Other work, though quite interesting, can require a significant amount of additional infrastructure to support new cell designs. For example, one recent report innovatively mitigates $\mathrm{Al}$ corrosion at open circuit through oil displacement. In this case, an estimate of the energy density was made by the authors $\left(680 \mathrm{Wh} \mathrm{kg}^{-1}\right)^{18}$. However, a combination of the complex cell design and the additional weight for the elements required to facilitate the continuous flow of electrolyte and the storage and handling of the oil could limit the practical application of this type of battery."

All versions of the Perspective have now been amended.

Published online: 16 February 2021

https://doi.org/10.1038/s41560-021-00791-z

(C) The Author(s), under exclusive licence to Springer Nature Limited 2020 